\title{
Decadal climate variability in the tropical Pacific: characteristics, causes, predictability and prospects
}

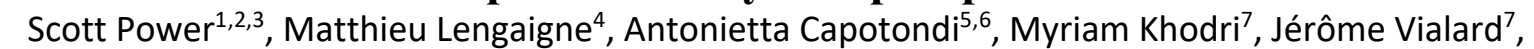
Beyrem Jebri ${ }^{7}$, Eric Guilyardi ${ }^{7,8}$, Shayne McGregor ${ }^{2}$, Jong-Seon Kug ${ }^{9}$, Matthew Newman ${ }^{5,6}$, Michael J. McPhaden ${ }^{10}$, Gerald Meehl ${ }^{11}$, Doug Smith ${ }^{12}$, Julia Cole ${ }^{13}$, Julien Emile-Geay ${ }^{14}$, Daniel Vimont ${ }^{15}$, Andrew T. Wittenberg ${ }^{16}$, Mat Collins ${ }^{17}$, Geon-II Kim ${ }^{9}$, Wenju Cai ${ }^{18,19,20}$, Yuko Okumura ${ }^{21}$, Christine Chung ${ }^{22}$, Kim M. Cobb $^{23}$, François Delage ${ }^{22}$, Yann Y. Planton ${ }^{10}$, Aaron Levine ${ }^{10}$, Feng Zhu ${ }^{21}$, Janet Sprintall ${ }^{24}$, Emanuele Di Lorenzo $^{25}$, Xuebin Zhang ${ }^{18}$, Jing-Jia Luo ${ }^{26}$, Xiaopei Lin ${ }^{19,20}$, Magdalena Balmaseda ${ }^{27}$, Guojian Wang ${ }^{18}$, Benjamin J. Henley ${ }^{2,3}$

\section{Corresponding Author:}

July 27, 2021

Professor Scott B. Power, Dip. Ed.

Director, Centre for Applied Climate Sciences, University of Southern Queensland

Email: scott.power@usq.edu.au; Phone: +61 400650 48; ORCID ID: 0000-0002-9596-4368.

\footnotetext{
${ }^{1}$ Centre for Applied Climate Sciences, University of Southern Queensland, QLD, Australia

${ }^{2}$ School of Earth, Atmosphere, and Environment, Monash University, VIC, Australia

${ }^{3}$ ARC Centre of Excellence for Climate Extremes, Monash University, VIC, Australia

${ }^{4}$ MARBEC, University of Montpellier, CNRS, IFREMER, IRD Sète, France

${ }^{5}$ Cooperative Institute for Research in Environmental Sciences, University of Colorado, Boulder, CO, USA

${ }^{6}$ Physical Sciences Laboratory, NOAA, Boulder, CO, USA

${ }^{7}$ LOCEAN, Sorbonne Universités/UPMC/CNRS/IRD, Paris, France

${ }^{8}$ National Centre of Atmospheric Science, University of Reading, Reading, UK

${ }^{9}$ Division of Environmental Science and Engineering, Pohang University of Science and Technology (POSTECH), Pohang, South Korea

${ }^{10}$ NOAA/Pacific Marine Environmental Laboratory, Seattle, WA, USA

${ }^{11}$ National Center for Atmospheric Research, Boulder, CO, USA

${ }^{12}$ Met Office Hadley Centre, Exeter, UK

${ }^{13}$ Department of Earth and Environmental Sciences, University of Michigan, Ann Arbor, USA

${ }^{14}$ Department of Earth Sciences, University of Southern California, Los Angeles, USA

${ }^{15}$ Atmospheric and Oceanic Science, University of Wisconsin-Madison, Madison, Wisconsin

${ }^{16}$ NOAA Geophysical Fluid Dynamics Laboratory, Princeton, NJ, USA

${ }^{17}$ College of Engineering, Mathematics and Physical Sciences, University of Exeter, Exeter, EX4 4QE, UK

${ }^{18}$ Centre for Southern Hemisphere Oceans Research, CSIRO Oceans and Atmosphere, Hobart 7001, TAS, Australia

${ }^{19}$ Frontier Science Center for Deep Ocean Multispheres and Earth System and Laboratory of Physical

Oceanography, Ocean University of China

${ }^{20}$ Qingdao National Laboratory for Marine Science and Technology, Qingdao 266003, China

${ }^{21}$ Institute for Geophysics, Jackson School of Geosciences, The University of Texas at Austin, Austin, Texas

${ }^{22}$ Bureau of Meteorology, Docklands, VIC, Australia

${ }^{23}$ School of Earth and Atmospheric Sciences, Georgia Institute of Technology, Atlanta, USA

${ }^{24}$ Scripps Institution of Oceanography, University of California San Diego, La Jolla, California, USA

${ }^{25}$ Program in Ocean Science \& Engineering, Georgia Institute of Technology, Atlanta, Georgia, USA

${ }^{26}$ Institute for Climate and Application Research (ICAR)/CICFEM/KLME/ILCEC, Nanjing University of Information Science and Technology, Nanjing, China

${ }^{27}$ European Centre for Medium-Range Weather Forecasts, Reading, United Kingdom
} 


\section{Structured Abstract}

\section{BACKGROUND}

Tropical Pacific Decadal climate Variability and change (TPDV) affects the global climate system, extreme weather events, agricultural production, streamflow, marine and terrestrial ecosystems, and biodiversity. While major international efforts are underway to provide decadal climate predictions, there is still a great deal of uncertainty about the characteristics and causes of TPDV, and the accuracy to which it can be simulated and predicted. Here we critically synthesize what is currently known and what is not known, and provide recommendations to improve our understanding of TPDV and our ability to predict it.

\section{ADVANCES}

TPDV is evident in instrumental records, paleoclimate records over past millennia, and climate models. TPDV can occur spontaneously as "internal" variability, as is largely the case in the central equatorial Pacific, or in response to "external" forcing. While internal TPDV arises to a large extent as a residual of independent El Niño-Southern Oscillation events, it can also result from oceanic processes occurring at decadal timescales involving the upper-ocean overturning circulation known as subtropical-tropical cells, and in response to internal atmospheric variability in the extratropical Pacific and changes in sea surface temperature in other ocean basins. "Externally-forced" TPDV, in the form of mean-state changes that unfold on decadal timescales or forced decadal variability, can be driven by anthropogenic (e.g., greenhouse gas (GHG) increases, sulphate aerosols changes) and natural processes (e.g., volcanic eruptions). External forcing can also affect the behavior and characteristics of internal TPDV. 
In the western tropical Pacific, GHG-forced warming has reached levels that are unprecedented in the historical record. Further greenhouse warming in the equatorial Pacific will ensure that recordsetting high temperatures will be experienced for decades to come. Increases in equatorial precipitation and in precipitation variability in parts of the tropical Pacific, and a southward expansion of the southern hemisphere Hadley Cell, are projected by climate models with some confidence. Yet projected changes in eastern equatorial Pacific surface temperature, and changes in the strength of the Walker Circulation and trade winds, remain very uncertain.

Skill in decadal predictions of temperature in the western Pacific is apparent, though it appears to be largely underpinned by GHG warming. There are also indications of multiyear skill in predicting some biogeochemical quantities important for fisheries and the global carbon budget.

The limited length of the instrumental records, the scarcity of paleoclimate data, and TPDV representation biases in climate models have so far prevented a complete characterization and understanding of TPDV and have limited our ability to predict TPDV.

\section{OUTLOOK}

While several mechanisms have been proposed to explain TPDV, their relative importance as sources of decadal prediction remains unclear. Issues in need of greater understanding include the role played by the upper ocean overturning circulation in controlling tropical Pacific sea surface temperatures at decadal timescales, the impact of external forcing on the Walker circulation and characteristics of internally-generated TPDV, and the extent to which sea surface temperature variability in other basins drives TPDV. A better understanding of the origin and spatial pattern of 
65 current predictive skill is also needed. Improving predictions and projections requires 66 improvements in the quality, quantity, and length of instrumental and paleoclimate records, in the 67 performance of climate models and data assimilation methods used to make predictions. 


\section{Introduction}

Climate variability in the tropical Pacific affects global climate on a wide range of timescales. On interannual timescales, the tropical Pacific is home to the El Niño-Southern Oscillation (ENSO), the most energetic and influential climate phenomenon in the world (1). Less well known is that decadal variations and changes in the tropical Pacific, referred to here collectively as "Tropical Pacific Decadal Variability" (TPDV), also profoundly affects the climate system. In the following, we will use TPDV to refer to any form of decadal climate variability or change that occurs in the atmosphere, the ocean and over land within the tropical Pacific. "Decadal" is used here in a broad sense to encompass multiyear through multidecadal timescales, including variability about the mean-state on decadal timescales, externally forced mean-state changes that unfold on decadal timescales, and decadal variations in the behavior of higher-frequency modes like ENSO.

Naturally occurring, spontaneously generated TPDV can arise in the absence of any change to external forcing (e.g., greenhouse gas (GHG) increases or volcanic eruptions). Climate scientists refer to such variability as "internally-generated" or "internal" variability, and will be referred to here as "internal TPDV" (2). Internal TPDV affected the rate at which globally-averaged surface air temperature rose over the past century. This was dramatically illustrated by the recent and highly publicized "global warming slow-down", when decadal surface cooling in the eastern equatorial Pacific (shading in Fig. 1A) associated with a major redistribution of heat in the subsurface ocean offset the anthropogenic global warming trend at the turn of the $21^{\text {st }}$ century $(3,4)$ (bottom curve on Fig. 1D). Trade winds intensification associated with this cooling also contributed to rapid sealevel rise in the western Pacific during recent decades (5) (contours in Fig. 1A). More generally, internal TPDV has further been reported to modulate drought, wildfire, floods, extreme weather, 
91 polar sea-ice extent $(6,7)$, decadal variations in the impact that ENSO has on rainfall, river flow and agricultural production, and the skill with which ENSO impacts can be predicted, as demonstrated for Australia (8). Uncertainty in the magnitude of internal TPDV simulated in global climate models may also be linked to uncertainty in simulated climate sensitivity ( 9 ) - a measure of the degree of global warming that occurs in response to anthropogenic increases in atmospheric GHG concentrations (10).

The tropical Pacific also changes in response to external forcing, including GHG increases, volcanic eruptions and anthropogenic aerosols. This component of TPDV will be referred to as "external TPDV'. The observed low-frequency sea-surface temperature (SST) evolution over the western tropical Pacific warm-pool is dominated by a long-term warming trend similar to the global anthropogenic warming signal (bottom curves of Fig. 1D), that has been linked to a drying trend in the East Asian monsoon (11). Further warming in the region is also expected to reduce coastal fish populations, shift tuna distribution eastward, cause record-breaking high temperatures to occur more often (12) and fundamentally alter coral reefs, with major impacts on biodiversity, Pacific Island communities, and livelihoods $(12,13)$.

Major international efforts are underway to provide decadal climate predictions that are intended to help decision makers plan for coming years and decades (14) that take both internally generated and externally-forced TPDV into account, as they will both influence future climate. The enormous challenges currently faced by groups producing decadal predictions demand a better understanding of the mechanisms of TPDV. To that end, here we synthesize our current understanding of TPDV, its spatial and temporal characteristics, its many proposed mechanisms - both natural and 
114 anthropogenic and the interactions between them, and the current ability of state-of-the-art

115 modeling and prediction systems to simulate and predict TPDV. A wide and diverse array of

116 evidence is used, from historical records, instrumental and paleoclimate observations, mathematical

117 models of Earth's climate, and decadal prediction systems, to assess the degree of confidence we

118 have in proposed mechanisms and the extent to which those processes provide a degree of

119 predictability $(2,14,15)$.

121 Advances

\section{Observed TPDV}

123 Decadal SST fluctuations peak in the equatorial central/eastern Pacific (contours in Fig. 1B),

124 alternating between decadal periods of anomalously warm and cold phases (top panel of Fig. 1D).

125 This evolution broadly matches the positive and negative phases of the Interdecadal Pacific

126 Oscillation (8) (represented as vertical shading in Fig. 1D), characterized by opposite SST and sea-

127 level signals in the eastern and western tropical Pacific (Fig. 1A). While important on decadal

128 timecales, this variability only modestly contributes to total SST variations in the equatorial eastern

129 Pacific (shading in Fig. 1B), which are largely dominated by ENSO-related interannual SST

130 fluctuations. The relative contribution of TPDV is considerably larger in the western Pacific, where

131 the low-frequency SST signal is dominated by a long-term warming trend similar to the global

132 anthropogenic warming signal (bottom curves of Fig. 1D). Consequently, internal TPDV, estimated

133 here in the 8-40 years range, dominates in the central Pacific and in off-equatorial bands in the

134 eastern part of the basin, especially in the northern Hemisphere. Internal TPDV has a weak signature

135 in the western tropical Pacific (Fig. 1C), where the longer timescales of external TPDV prevail 136 instead. 
138 Confidently characterizing TPDV is complicated by the short historical record. Indeed, historical

139 observations of the tropical Pacific are sparse before the mid-20th century, which creates

140 uncertainty in tropical Pacific SST records prior to 1950. Paleoclimate records offer key

141 complementary information extending further into the past (Fig. 1D). A recent synthesis of

142 dozens of monthly- to annually-resolved Pacific coral records exhibit strong decadal variability

143 over the last four centuries (16). In particular, isotopic measurements from corals in the central

144 and southwest tropical Pacific $(17,18)$ (white dot and star in Fig. 1A) display a monotonic trend

145 toward warmer and wetter conditions over the twentieth century (blue curves in Fig. 1D),

146 supporting the central Pacific rainfall increase in response to anthropogenic forcing found in

147 models. On shorter timescales, these timeseries display opposite signals, capturing the contrast

148 between warm/wet and cold/dry regions related to the internal TPDV pattern (Fig. 1A). Recent

149 advances in paleoclimate data assimilation have enabled the construction of gridded tropical

150 Pacific SST fields extending through the last millennium (19), that match qualitatively well the

151 observed SST evolution over the instrumental period (Fig. 1D). These reconstructions, however,

152 exhibit increasing uncertainty as fewer records become available back in time (Fig. 1D, gray

153 envelopes).

154

155

Internal TPDV

156 The dominant internal TPDV SST signal can be characterized by the leading empirical orthogonal 157 function and related Principal Component of 8-40 year variability of tropical Pacific SST (Fig. 2,

158 A and B), which accounts for about half of the tropical Pacific SST variability in the 8-40 year 159 timescale (contours in Fig. 1C). The related SST pattern throughout the entire Pacific basin can then 
160 be obtained through linear regression upon this principal component. This internal TPDV SST

161 pattern (Fig. 2A; shading) strongly resembles the ENSO SST pattern in the tropics (Fig. 2E), but

162 has a generally broader latitudinal extent $(20,21)$. This pattern is also associated with a zonal seesaw

163 in tropical Pacific mean sea-level pressure, as described by the Southern Oscillation index (Fig.

164 2B), a measure of the difference in sea level pressure between Tahiti and Darwin, leading to the

165 anti-correlation between this index and the SST-based internal TPDV index at decadal timescales

166 (Fig. 2B). The internal TPDV SST pattern (Fig. 2A) is consistent with the patterns of variability

167 associated with the Interdecadal Pacific Oscillation (8) over the Pacific basin and the Pacific

168 Decadal Oscillation in the North Pacific (22), highlighting the important role of the tropical Pacific

169 in forcing and synchronizing decadal variability in both hemispheres (22).

170

171 The simplest explanation for internal TPDV - the null hypothesis - is that it arises as a residual of

172 largely independent ENSO events $(21,23,24)$. We hence first establish the extent to which observed

173 TPDV might result from decadal averages of ENSO events that are randomly distributed, without

174 modification by independent decadal dynamics or decadal clustering through nonlinear interactions.

175 In this view, the random occurrence of decadal epochs with a larger number of El Niño (La Niña)

176 can be expected to result in an El Niño (La Niña)-like residual SST anomaly (21). The null hypothsis

177 is supported by the good correspondence between the time series of the leading pattern of internal

178 TPDV and the relative number of El Niño and La Niña events during partially-overlapping 8-year

179 periods (Fig. 2B). In addition, each ENSO event is not a static pattern, but undergoes an evolution

180 from a precursor phase (Fig. 2D), through a mature phase (Fig. 2E), to a decay phase (Fig. 2F), so

181 that the average over this seasonal evolution across multiple events can result in a latitudinally

182 broader pattern (Fig. 2C) very similar to the pattern in Fig. 2A (24). 
184 This picture is further modified by ENSO asymmetries. For example: the strongest El Niño events 185 are larger than the strongest La Niña events; La Niña events tend to last longer than El Niño events; 186 and strong El Nino events tend to occur further east than strong La Niña events, impacting the 187 details of TPDV (25). Differences in spatial patterns, with some events having greatest amplitude 188 in the central or eastern tropical Pacific $(1,26)$ may result in mean pattern differences during 189 different decadal epochs (25), which may themselves occur purely by chance $(25,27)$.

190

191 Whether decadal changes in the background state, even if randomly forced, feedback and modulate

ENSO characteristics is a focus of current research (28). To go beyond the null hypothesis, therefore, we would need evidence that slow oceanic processes provide sources of decadal predictability beyond the ENSO timescale. For example, the ocean integration of ENSO-related surface fluxes may result in low-frequency SST variations with enhanced decadal predictability, as illustrated in a modeling context (21).

In addition, changes in the strength of the wind-driven upper-ocean overturning circulation, known as the Subtropical-Tropical Cells (STCs), which connect the subtropical and equatorial regions, have been related to decadal variations of equatorial SSTs in both observations (29) and models $(30,31)$. As schematically depicted in Fig. 3A, the STCs include subsurface equatorward flow, equatorial upwelling, and poleward flow in the surface Ekman layer, so that a strengthening (weakening) of the STCs results in enhanced (reduced) equatorial upwelling of cold subsurface waters, impacting equatorial SSTs. The adjustment of the STCs to changes in surface wind forcing is accomplished through the propagation of oceanic Rossby waves (30) that travel to the western 
ocean boundary, and then along the boundary to the equator as coastal-trapped waves, where they alter the depth of the equatorial thermocline and influence SST anomalies (Fig. 3A) $(32,33)$. Since Rossby waves are more efficiently excited by wind anomalies with larger spatial scales and longer timescales, they can dynamically "filter" the wind forcing, and contribute to an enhancement of low-frequency power (34).

Other modeling studies suggest that temperature anomalies subducted in the subtropics can reach the equatorial thermocline and influence equatorial SSTs (35), especially when they are densitycompensated by associated salinity anomalies (so-called "spiciness" anomalies) and can then propagate toward the equator along mean density surfaces with minimal dissipation (36). While the ability of spiciness anomalies to reach the equator from their source regions has been recently demonstrated in a modeling context (36), their impact on equatorial SSTs in nature remains to be determined.

The above ocean processes occurring on decadal timescales are mostly wind-forced. In particular, modeling studies (31) indicate that subtropical winds play a key role in altering the strength of the STCs, but the origin of these anomalous winds is still unclear. Extra-tropical influences could be a source of sub-tropical wind variations. For example, internal atmospheric variability in the northern midlatitudes during winter can create subtropical SST and wind anomalies that persist through summer due to strong air-sea coupling (37), developing into a SST pattern that extends from the coast of California toward the central-western equatorial Pacific (Fig. 2D), known as the "North Pacific Meridional Mode" (38). Similarly, an anomalous SST pattern, known as the South Pacific Meridional Mode (39), can develop along the coast of South America (Fig. 2D). These 
Meridional Modes are considered ENSO precursors, but their associated winds could also provide anomalous forcing for the slow tropical oceanic processes described above (40). As ENSO precursors, they are also part of a seasonal progression from the extra-equatorial ENSO precursor stage, to ENSO development, to extra-tropical ENSO teleconnections that can act as a filter of decadal variance in the Pacific basin (41). Climate model sensitivity experiments, where the North and South Pacific Meridional Modes were alternatively suppressed (42), suggest a potentially more important influence of the South Pacific on internal TPDV, consistent with other model-based studies $(43,44)$. SST anomalies in the Atlantic and Indian Oceans could also influence these tropical Pacific winds $(45,46)$, as discussed below.

Finally, changes in subtropical-tropical winds may arise as a response to the equatorial SST anomalies themselves, as shown in some modeling studies $(32,47)$. In this view, atmospheric teleconnections triggered by the tropical SST anomalies at decadal timescales alter the extraequatorial atmospheric circulation and produce wind anomalies of the opposite sign that force a phase reversal of the decadal cycle. This view of internal TPDV as arising from low-frequency processes that are independent of ENSO, with important implications for decadal predictability, remains very challenging to demonstrate observationally, due to the insufficient duration of the instrumental record in the presence of climate noise that may obscure the various deterministic links.

\section{Representation of internal TPDV in climate models}

In practice, evaluating internal TPDV simulated by climate models is challenging because: (i) the instrumental record is relatively short (e.g., Fig. 1D); (ii) relatively few multi-century paleoclimate 
252 records exist for the core regions of internal TPDV; (iii) internal TPDV in climate model 253 simulations exhibits large changes from one century to the next (48); and (iv) the characteristics 254 of internal TPDV vary markedly from model to model (Fig. 4).

256 As illustrated in Fig. 4, climate models still display major deficiencies in simulating key aspects 257 of internal TPDV $(49,50)$. For example, most models capture to first order the observed SST 258 pattern but the equatorial Pacific warming extends too far to the west (compare shading in Fig. 4A 259 and Fig. 4B; see also (49)), as do simulated ENSO SST patterns (51). Models also markedly 260 underestimate sea-level signals in the tropical western Pacific and extra-tropical central Pacific 261 associated with internal TPDV (compare contours on Fig. 4A and Fig. 4B). Similarly, the

262 magnitude of simulated internal TPDV varies considerably from one model to another and is underestimated by a majority of models not only in terms of SST (Fig. 4C), but also in terms of trade wind strength (Figs. 4A vs. 4B) and associated mean-sea-level pressure gradients in the tropical Pacific atmosphere $(4,52)$. This underestimation partly arises because ENSO simulations in most models tend to be too quasi-biennial and not persistent enough (53), impeding the ability of models to generate decadal anomalies through the null hypothesis (52). As a consequence, while all models exhibit some link between ENSO decadal variability and internal TPDV, they strongly underestimate the strength of this relationship (Fig. 4D).

\section{Sources of externally-forced TPDV}

As mentioned above, external radiative forcing from natural (e.g., volcanic eruptions and solar variability) and anthropogenic (e.g., GHGs, ozone and sulfate aerosols) sources also contribute to TPDV. The resulting external TPDV is directly related to decadal variability in the forcing (e.g., 
275 intermittent volcanic eruptions, slowly-increasing GHGs, varying anthropogenic aerosols 276 emission), with possible contributions from the slow adjustment timescale of the ocean. Here, we 277 examine the expected tropical Pacific responses from both anthropogenic and natural external 278 forcing, which are represented schematically in Figure 3B.

280 GHGs such as carbon dioxide are the major source of anthropogenic climate warming and have 281 been increasing steadily over past decades. Despite the spatially uniform nature of well-mixed 282 GHGs, the warming of the ocean surface simulated by climate models exhibits substantial spatial 283 variations (54). Most models project an enhanced warming in the equatorial Pacific (Fig. 3B), 284 giving rise to tropical rainfall changes (54) altering global teleconnection patterns, increasing the 285 frequency of extreme ENSO events (55) and regulating the magnitude of climate sensitivity (56).

286 One study concluded that a GHG-forced enhancement of oceanic stratification leads to increasing 287 Rossby wave speed, which decreases the amplitude and shortens the period of internal TPDV (57), 288 whereas another study using a single model found GHG enhanced the amplitude of internal 289 decadal variability (56).

291 Unlike GHGs, anthropogenic tropospheric aerosols display large spatio-temporal variations 292 because of localised emission sources, and act to cool global surface temperature by reflecting 293 sunlight. Models suggest that they induce SST and rainfall changes that are similar in pattern but 294 opposite in sign to those of GHGs, especially in the tropical Pacific (59), hence weakening the 295 GHG-induced warming. 
297 Large volcanic eruptions can also contribute to external TPDV by injecting aerosols into the 298 stratosphere. This cools the troposphere for a year or more (2) and the ocean for up to a decade 299 thereby temporarily reducing the rate of global thermosteric sea-level rise (60). While the impact 300 of volcanic eruptions on global temperature is evident, their contribution to external TPDV is less 301 clear $(61,62)$. Volcanic eruptions have been suggested to (i) influence ENSO (63) and, by 302 inference, TPDV, and (ii) to contribute to cooling the western Pacific warm pool on decadal scales 303 (64). Models tend to simulate enhanced, long-term cooling in the eastern equatorial Pacific, but 304 observations are still too sparse to adequately test these model results (65).

\section{Confidence in the attribution of observed changes and future projections}

307

308

309

310

311

312

313

314

315

316

317

318
Although GHG forcing generally dominates external TPDV at multi-decadal and longer timescales, anthropogenic aerosols and volcanic eruptions may have significantly contributed to regional tropical SST variations over recent decades $(61,62)$. Relatively small decadal changes in top-of-atmosphere solar irradiance have presumably a smaller influence than GHG, although the 11-yr solar cycle, amplified by coupled atmosphere-ocean processes, has been proposed to modulate the Walker Circulation on decadal timescales (66). Timescales involved in internal and external TPDV overlap, which makes them difficult to distinguish from one another, especially when considering the relatively short climate record and potential errors in models. As a result, there are varying degrees of confidence in the attribution of some of the observed trends to either internal or external forcing. 
In the following section, we discuss key aspects of future model projections in the tropical Pacific, comparing them with the observational record.

\section{- Western Pacific warming}

The western Pacific exhibits a prominent warming trend since the 1950s (Fig. 1D; Fig. 5A), which dominates the evolution of SST in this region (Fig. 1B). This warming trend is accurately captured by historical simulations (compare Fig. 5A and Fig. 5B) and clearly stands out against the weak background natural variability in this region (Fig. 5C), reflecting the fact that the signal-to-noise ratio for this projected warming is among the highest in the world (12). Coral-based SST estimates indicate that such a warming period is likely unprecedented in the western Pacific region throughout the last 1,250 years (67). The warming trend for air temperatures over land in west Pacific island countries is so large that every year since the early 1990s has been warmer than all years prior to 1970 (68). The resulting increase of the western Pacific warm-pool size has confidently been attributed to GHG forcing arising from human activity $(68,69)$ although remote influence from the natural multidecadal climate variability in the Atlantic (70) and major volcanic eruptions (64) may also have modulated the SST warming rate there.

\section{- Hadley Cell}

While recent observational datasets significantly differ before the 1950's, they consistently report a southward expansion of the southern edge of the Southern Hemisphere Hadley Cell since 1979 (Fig. 5D; (71)). Although internal climate variability also contributed, this widening over the last 40 years can confidently be attributed to the combined effect of ozone depletion and rising GHGs (Fig. 3B; Fig. 5D; (71)). The mechanism behind this widening is still subject to debate but likely 
342 reflects how subtropical atmospheric baroclinic eddies respond to tropospheric (GHGs) and 343 stratospheric (ozone) changes in the atmospheric background state (71). This southward expansion 344 is associated with a lower rate of warming (Fig. 5AB) and ocean acidification $(54,72)$ in the 345 southeastern tropical Pacific than in the rest of the tropics, probably driven by an intensification of 346 the southeastern Pacific trade winds, which strengthen the Peru-Chile upwelling system near the 347 coast, increase heat loss through air-sea fluxes and modulate the oceanic mixed layer offshore (68). 348 Models also project a widening of the Northern Hemisphere Hadley Cell that is currently not yet 349 detectable in observations due to a larger influence of internal climate variability $(71,73)$. As illustrated in Fig. 5B, E and F, most state-of-the-art models project a weakening of the equatorial trade winds and Walker Circulation and a faster warming rate at the equator, in 354 particular in the eastern equatorial Pacific (55). In agreement with instrumental observations and historical simulations $(51,74)$ central tropical Pacific corals also point to a wet trend over the 20th century (Fig. 1D), accompanied by even wetter periods during positive phases of the Interdecadal Pacific Oscillation (18). A leading explanation for the Walker Circulation weakening is that rainfall increases less in models than predicted by the Clausius-Clapeyron relation, implying increased atmospheric stability and a reduced mass-flux between the boundary layer and free atmosphere, resulting in a weakened Walker Circulation (75). The enhanced equatorial eastern

361 Pacific warming has been explained by a feedback loop between the weaker evaporative cooling 362 in the cold tongue (54) and reduced trade winds, and a limitation of the SST increase by cloud 363 feedbacks over the West Pacific (55). Recent studies also suggest that the subtropical 364 anthropogenic warming also contributes to the enhanced equatorial warming by slowly making its 
way to the equatorial thermocline through the oceanic STCs $(76,77)$. There is, however, no consensus to date on the dominant mechanism responsible for the projected equatorial Pacific SST gradient changes.

A key uncertainty of external TPDV is that simulated changes do not match recent observed historical trends over, e.g., 1981-2012 (4,52), which are characterized by a marked strengthening of the Walker Circulation over this period. Such signals are typical of internal TPDV (Fig. 4AB). Indeed, recent studies attribute a large part of this recent observed evolution in the central equatorial Pacific to internal TPDV $(4,52,78)$, which is a strong contributor to SST variations in this region (Fig. 1C). This is illustrated by the relatively large model ensemble spread displayed in Figures $5 \mathrm{E}$ and F, which largely encompass the observed SST and surface wind evolution.

On the other hand, many recent studies suggest plausible mechanisms by which external forcings might also have contributed to the recent strengthening. For example, model results indicate that the reduction in tropospheric sulfate aerosol emissions from North America and Europe and the concurrent increase in China - perhaps augmented by changes driven by volcanic eruptions ( 62 , 79) - might have contributed to the recent tropical Pacific cooling (61). Other modeling studies suggest that the observed faster warming in the Indian and/or Atlantic relative to the Pacific Ocean are conducive to enhanced trades in the Pacific and reinforced the recent tropical Pacific cooling (46). Increasing GHGs likely contributed to this observed Indian-Pacific differential warming, but their contribution to the enhanced Atlantic warming is unclear (80). Finally, some models reproduce the observed Walker Circulation strengthening and equatorial cooling (81), with a plausible mechanism related to the poleward export of the added equatorial Pacific heat by the 
sustained meridional divergence of the near-equatorial upper-ocean currents $(82,83)$. Model-based studies further suggest that the fast equatorial cooling related to this oceanic thermostat mechanism will be followed by a slower transition to an enhanced equatorial warming and Walker Circulation weakening, in response to subtropical warm anomalies advected into the equatorial thermocline by the STCs $(76,77)$.

It is thus unclear from current literature if the recent observed Walker Circulation and cold tongue strengthening is a response to external forcing that is only reproduced by a few models, or if it simply arises from internal variability hiding a subtle opposite secular trend (78). This results in a rather low confidence in the projected weakening of the Walker Circulation and related enhanced equatorial eastern Pacific warming in climate models. Several studies indeed argue that the enhanced equatorial warming in most climate projections may arise from common present-day climate model biases within the tropical Pacific (84) or from an underestimation of interbasin interactions $(45,46,84)$. Confidence in these projections is further reduced by the large uncertainties on the impact of aerosols on radiation, cloud microphysics and SST (85). These caveats imply that it is currently not possible to conclude with confidence whether GHG forcing has weakened, strengthened, or had no effect on the Walker Circulation and equatorial upwelling.

\section{- Changes in ENSO}

Improving the reliability of these projections is key, partly because projected changes in the equatorial zonal SST gradient strongly influence ENSO in climate models (55). The projected warming pattern in the equatorial Pacific in most climate models indeed increases ENSO-driven and decadal precipitation anomalies in part of the tropical Pacific $(51,55,74)$, and is tied to an 
411 increase in the amplitude of ENSO anomalies (55). Recent paleo-climatic evidence suggests that 412 the increase in ENSO variability since the 1950s stands out in the context of the past millennia 413 (86), lending support to the inter-model agreement on increased ENSO-driven precipitation 414 variability under greenhouse warming. These findings have significant implications, given the 415 large societal impacts of projected changes in ENSO, and the fact that any increase in ENSO416 driven precipitation variability (51) or the frequency of extreme ENSO states (55) may energize 417 internal TPDV through the various forms of our null-hypothesis $(21,24,25)$.

\section{Outlook}

420 Predicting the climate of the tropical Pacific over the next decade and beyond, including 421 precipitation, temperature, sea-level, and biogeochemistry, would have far-reaching societal and environmental benefits. However, because of the partially chaotic nature of the climate system, 423 decadal predictions can, at best, provide an outlook of annual to multi-year average conditions or 424 risks, rather than a more detailed picture of daily or seasonal conditions (2). A decadal prediction 425 would be typically expressed in terms of probabilities, such as the probability that temperature in 426 the tropical Pacific averaged over the next five years will exceed the temperature in the tropical 427 Pacific averaged over the past 30 years. While the changes in average conditions may be small, 428 they can produce marked differences in the probability of extremes (12).

430 Experimental prediction systems have been developed $(2,14)$ to exploit any predictability arising 431 from the mechanisms discussed in the previous sections. Results from an ensemble prediction 432 system suggests that initialisation with observations in much of the tropical Pacific tends to 433 contribute towards predictive skill for surface temperature, for forecast lead times only up to 
434

435

436

437

438

439

440

441

442

443

444

445

446

447

448

449

450

451

452

453

454

455

456

457

1

approximately two years (Fig. 6A) and is mostly associated with predictability arising from ENSO (87), though another study concluded that trans-basin climate variability connected with TPDV can be predicted up to three years ahead (46). It might also be that climate models underestimate the degree of skill that actually exists in the real world (88). At longer lead times, skill arises mainly from external forcing $(2,89)$ (Fig. 6A).

While predictive skill of decadal average SST is found in most of the tropical Pacific $(15,87)$ (Fig. 6B), it is not evident everywhere. In particular, there is limited skill in the central tropical Pacific north of the equator, extending to the northeast Pacific (Fig. 6B). This is an important region because SST variability there can impact climate in many parts of the world. This low skill may be because the intrinsic predictability of internal variability beyond two years is genuinely low there and any predictable forced response is weak compared with unpredictable internal variability. Alternatively, the combined impact of internal variability and the externally-forced signal may be predictable but the models might miss or misrepresent key mechanisms underpinning the predictability. If this is the case, then the impact of TPDV on ENSO behaviour might also be currently underestimated.

A significant advancement identified in this review is that skill in decadal predictions of SST in the western Pacific is apparent in the last two generations of dynamical decadal prediction systems (2) (Fig. 6B). While it is likely that this primarily arises from anthropogenic warming, climate models also simulate substantial externally-forced decadal variability in this region about the longterm warming trend (Fig. 5C). This suggests that other types of external forcing have also contributed to TPDV in west Pacific SSTs. Whether this enhances predictability in West Pacific SSTs or not is still unclear. 
459 There are indications that in the tropical Pacific, multi-year variability in some biogeochemical 460 quantities important for fisheries and the global carbon budget such as net primary production and 461 carbon dioxide uptake can be predicted with greater skill than SST $(90,91)$. This may be because 462 the biogeochemical quantities are more influenced by subsurface and spatially integrated 463 quantities, which tend to exhibit greater predictability than does SST (21). Limited evidence also 464 suggests that there may be some skill in predicting atmospheric sea-level pressure and sea-surface 465 height (92), changes in the phase of the Interdecadal Pacific Oscillation (e.g.; (93, 94), related 466 precipitation averaged over the Asian-Australian monsoon, Australia more broadly, and western 467 North America (95), and soil moisture - with implications for drought and wildfire - over parts of 468 the southwestern U.S. (6).

470 In summary, our review of TPDV predictability finds that although responses to anthropogenic 471 GHG increases offer predictability in some variables (e.g., Fig. 5C; Fig. 6A and B), confidence in 472 the modeled response in the tropical Pacific is generally low; predictability from tropospheric 473 aerosols is still debated; volcanic eruptions likely provide predictability immediately after the 474 eruption has occurred (63); changes in anthropogenic aerosols (e.g., due to industrial growth and 475 pollution aerosols) provide longer-timescale forcing; and TPDV arising from solar forcing likely 476 exists but is small in models compared with other sources of external forcing and unlikely to be a 477 significant source of predictability.

478

\section{The Way Forward}


480

481

This review has highlighted some important advances in our understanding of the tropical Pacific climate variability and change at decadal and longer timescales. It has also highlighted the complexity of the interactions between variations that occur naturally and those that are forced by external factors of both natural and anthropogenic origin, and the knowledge gaps and uncertainties associated with both components and their interactions. While several plausible mechanisms for both internal and externally-forced TPDV have been proposed, their relative importance and relevance to predictability needs to be further clarified. Specific open science questions include:

1. How important are oceanic processes involving the STCs in driving predictable decadal climate variations? Do the mechanisms involving STC variability and the associated wind forcing arise independently of ENSO? How large is the predictability associated with these oceanic processes?

2. How robust are climate model projections in the tropical Pacific and what are the dominant processes driving these changes? In particular, how will the Walker Circulation, equatorial SST and internal variability respond to future greenhouse gas increases?

3. Why do forecast systems appear to offer predictive skill in the western and southern tropical Pacific, but not in the north-eastern tropical Pacific?

Improvements in the quality, quantity, and length of observational records available for characterizing decadal variability are critical to address these science questions, and to initialize and verify decadal prediction systems. This will require sustaining and enhancing the ocean and climate observing systems, data rescue efforts to recover historical observations from data-sparse regions, and the development of new monthly- to annually-resolved paleoclimate records from 
502 TPDV centers of action, with a focus on obtaining multiple records in those regions to enhance 503 signal-to-noise ratios. Continued advances in paleoclimate data assimilation (19) will also be 504 critical for the integration of paleoclimate and instrumental observations with models to obtain 505 more complete and reliable fields.

506 While substantial model improvements have been made in recent decades for some features of the 507 climate system (10), models are still limited in their ability to accurately represent observed TPDV 508 and there are large model-to-model differences in the magnitude of simulated TPDV. As noted in 509 the Introduction, there is evidence suggesting that there may be a link between these differences 510 and model-to-model differences in global climate sensitivity. Improving the simulation of TPDV 511 might therefore yield a narrower range in climate sensitivities and greater clarity on our climatic 512 future.

513 Despite their shortcomings, climate models are essential tools for advancing our ability to 514 understand and predict future change in the tropical Pacific. The underlying causes of the 515 shortcomings are still elusive and dedicated efforts using novel approaches are required to identify 516 the major sources of errors in both local and remote feedbacks. Enhanced efforts on the specific 517 role of the STCs in driving TPDV in models may facilitate improved understanding of the 518 mechanisms involving variability of the STCs and their associated wind forcing. In the longer 519 term, improving climate models will be essential for achieving more realistic simulations, as well 520 as more reliable predictions and projections, of TPDV. Advances are expected from improvements 521 in: the representation of subgridscale processes; data assimilation into forecast systems; and 522 computing technology enabling higher spatial resolution, less reliance on parameterizations, 523 longer model runs, and larger ensemble sizes. 
560

561

562

563

564

565

566

567

568

\section{References}

1. A. Timmermann, S.-I. An, J.-S. Kug, F.-F. Jin, W. Cai, A. Capotondi, K. Cobb, M. Lengaigne, M. J. McPhaden, M. F. Stuecker, K. Stein, A. T. Wittenberg, K.-S. Yun, T. Bayr, H.-C. Chen, Y. Chikamoto, B. Dewitte, D. Dommenget, P. Grothe, E. Guilyardi, Y.G. Ham, M. Hayashi, S. Ineson, D. Kang, S. Kim, W. M. Kim, J.-Y. Lee, T. Li, J.-J. Luo, S. McGregor, Y. Planton, S. Power, H. Rashid, H.-L. Ren, A. Santoso, K. Takahashi, A. Todd, G. Wang, G. Wang, R. Xie, W.-H. Yang, S.-W. Yeh, J. Yoon, E. Zeller, X. Zhang, El Niño-Southern Oscillation complexity. Nature. 559, 535-545 (2018).

2. B. Kirtman, S. B. Power, A. J. Adedoyin, G. J. Boer, R. Bojariu, C. Ines, F. Doblas-Reyes, A. M. Fiore, M. Kimoto, G. Meehl, M. Prather, S. Abdoulaye, C. Schär, R. Sutton, G. J. van Oldenborgh, G. Vecchi, H.-J. Wang, Near-term Climate Change: Projections and Predictability. Fifth Assess. Rep. IPCC, 953-1028 (2013).

3. Y. Kosaka, S. Xie, Recent global-warming hiatus tied to equatorial Pacific surface cooling. Nature. 501, 403-407 (2013).

4. M. H. England, S. McGregor, P. Spence, G. A. Meehl, A. Timmermann, W. Cai, A. Sen Gupta, M. J. Mcphaden, A. Purich, A. Santoso, Recent intensification of wind-driven circulation in the Pacific and the ongoing warming hiatus. 4, 1-6 (2014).

5. X. Zhang, J. A. Church, Sea level trends, interannual and decadal variability in the Pacific Ocean. Geophys. Res. Lett. 39, 1-8 (2012).

6. Y. Chikamoto, A. Timmermann, M. J. Widlansky, M. A. Balmaseda, L. Stott, Multi-year predictability of climate, drought, and wildfire in southwestern North America. Sci. Rep. 7, 6568 (2017).

7. G. A. Meehl, J. M. Arblaster, C. M. Bitz, C. T. Y. Chung, H. Teng, Antarctic sea-ice expansion between 2000 and 2014 driven by tropical Pacific decadal climate variability. Nat. Geosci. 9, 590-595 (2016).

8. S. Power, T. Casey, C. Folland, A. Colman, V. Mehta, Inter-decadal modulation of the impact of ENSO on Australia. Clim. Dyn. 15, 319-324 (1999).

9. R. Colman, S. B. Power, What can decadal variability tell us about climate feedbacks and sensitivity? Clim. Dyn. 51, 3815-3828 (2018).

10. IPCC, Climate Change 2013: The Physical Science Basis. Contribution of Working Group I to the Fifth Assessment Report of the Intergovernmental Panel on Climate Change (Cambridge University Press, Cambridge, 2013).

11. L. Wang, G. Huang, W. Chen, W. Zhou, W. Wang, Wet-to-dry shift over Southwest China in 1994 tied to the warming of tropical warm pool. Clim. Dyn. 51, 3111-3123 (2018).

12. S. B. Power, F. P. D. Delage, Setting and smashing extreme temperature records over the coming century. Nat. Clim. Chang. 9, 529-534 (2019).

13. J. E. Johnson, V. Allain, B. Basel, J. D. Bell, A. Chin, L. X. C. Dutra, E. Hooper, D. Loubser, J. Lough, B. R. Moore, S. Nicol, in Springer Climate (2020), pp. 359-402.

14. Y. Kushnir, A. A. Scaife, R. Arritt, G. Balsamo, G. Boer, F. Doblas-Reyes, E. Hawkins, M. Kimoto, R. K. R. K. Kolli, A. Kumar, D. Matei, K. Matthes, W. A. W. A. Müller, T. O’Kane, J. Perlwitz, S. Power, M. Raphael, A. Shimpo, D. Smith, M. Tuma, B. B. Wu, Towards operational predictions of the near-term climate. Nat. Clim. Chang. 9, 94-101 
601

602

603

604

605

606

607

608

609

610

611

612

613

614

(2019).

15. G. J. Boer, G. J. Kharin, W. J. Merryfield, Differences in potential and actual skill in a decadal prediction experiment. Clim. Dyn., 868-874 (2019).

16. J. E. Tierney, N. J. Abram, K. J. Anchukaitis, M. N. Evans, C. Giry, K. H. Kilbourne, C. P. Saenger, H. C. Wu, J. Zinke, Tropical Corals 400 yrs reconstructed from coral archives. Paleoceanography. 30, 226-252 (2015).

17. E. P. Dassié, A. Hasson, M. Khodri, N. Lebas, B. K. Linsley, Spatiotemporal Variability of the South Pacific Convergence Zone Fresh Pool Eastern Front from Coral-Derived Surface Salinity Data. J. Clim. 31, 3265-3288 (2017).

18. S. C. Sanchez, N. Westphal, G. H. Haug, H. Cheng, R. L. Edwards, T. Schneider, K. M. Cobb, C. D. Charles, A Continuous Record of Central Tropical Pacific Climate Since the Midnineteenth Century Reconstructed From Fanning and Palmyra Island Corals: A Case Study in Coral Data Reanalysis. Paleoceanogr. Paleoclimatology. 35, 1-15 (2020).

19. R. Tardif, G. J. Hakim, W. A. Perkins, K. A. Horlick, M. P. Erb, J. Emile-Geay, D. M. Anderson, E. J. Steig, D. Noone, Last Millennium Reanalysis with an expanded proxy database and seasonal proxy modeling. Clim. Past. 15, 1251-1273 (2019).

20. Y. Zhang, J. M. Wallace, D. S. Battisti, ENSO-like interdecadal variability: 1900-93. J. Clim. 10, 1004-1020 (1997).

21. S. Power, R. Colman, Multi-year predictability in a coupled general circulation model. Clim. Dyn. 26, 247-272 (2006).

22. M. Newman, M. A. Alexander, T. R. Ault, K. M. Cobb, C. Deser, E. Di Lorenzo, N. J. Mantua, A. J. Miller, S. Minobe, H. Nakamura, N. Schneider, D. J. Vimont, A. S. Phillips, J. D. Scott, C. A. Smith, The Pacific decadal oscillation, revisited. J. Clim. 29, 4399-4427 (2016).

23. T. R. Ault, C. Deser, M. Newman, J. Emile-Geay, Characterizing decadal to centennial variability in the equatorial Pacific during the last millennium. Geophys. Res. Lett. 40, 3450-3456 (2013).

24. D. J. Vimont, The Contribution of the Interannual ENSO Cycle to the Spatial Pattern of Decadal ENSO-Like Variability. J. Clim. 18, 2080-2092 (2005).

25. G. Il Kim, J. S. Kug, Tropical pacific decadal variability induced by nonlinear rectification of El Niño-Southern Oscillation. J. Clim. 33, 7289-7302 (2020).

26. A. Capotondi, A. T. Wittenberg, J. Kug, K. Takahashi, M. J. McPhaden, in El Niño Southern Oscillation in a Changing Climate, M. J. McPhaden, A. Santoso, W. Cai, Eds. (John Wiley \& Sons, Inc, First., 2021), pp. 65-86.

27. M. Newman, S.-I. Shin, M. A. Alexander, Natural variation in ENSO flavors. Geophys. Res. Lett. 38 (2011), doi:10.1029/2011GL047658.

28. T. Sun, Y. M. Okumura, Impact of ENSO-Like Tropical Pacific Decadal Variability on the Relative Frequency of El Niño and La Niña Events. Geophys. Res. Lett. 47, 1-10 (2020).

29. M. J. McPhaden, D. Zhang, Slowdown of the meridional overturning circulation in the upper Pacific Ocean. Nature. 415, 603-608 (2002).

30. A. Capotondi, M. A. Alexander, C. Deser, M. J. McPhaden, Anatomy and Decadal Evolution of the Pacific Subtropical-Tropical Cells (STCs). J. Clim. 18, 3739-3758 (2005).

31. G. Graffino, R. Farneti, F. Kucharski, F. Molteni, The effect of wind stress anomalies and location in driving Pacific subtropical cells and tropical climate. J. Clim. 32, 1641-1660 
642

643

644

645

646

647

648

649

650

651

652

653

654

655

656

657

658

659

660

(2019).

32. G. A. Meehl, A. Hu, Megadroughts in the Indian Monsoon Region and Southwest North America and a Mechanism for Associated Multidecadal Pacific Sea Surface Temperature Anomalies. J. Clim. 19, 1605-1623 (2006).

33. A. Capotondi, M. A. Alexander, Rossby waves in the tropical North Pacific and their role in decadal thermocline variability. J. Phys. Oceanogr. 31, 3496-3515 (2001).

34. A. Capotondi, M. A. Alexander, C. Deser, Why Are There Rossby Wave Maxima in the Pacific at $10^{\circ} \mathrm{S}$ and $13^{\circ} \mathrm{N}$ ? J. Phys. Oceanogr. 33, 1549-1563 (2003).

35. J. Luo, S. Masson, S. Behera, P. Delecluse, S. Gualdi, A. Navarra, T. Yamagata, South Pacific origin of the decadal ENSO-like variation as simulated by a coupled GCM. 30, 47 (2003).

36. M. Zeller, S. McGregor, E. van Sebille, A. Capotondi, P. Spence, Subtropical-tropical pathways of spiciness anomalies and their impact on equatorial Pacific temperature. Clim. Dyn. (2020), doi:10.1007/s00382-020-05524-8.

37. D. J. Vimont, D. S. Battisti, A. C. Hirst, Footprinting: A seasonal connection between the tropics and mid-latitudes. Geophys. Res. Lett. 28, 3923-3926 (2001).

38. J. C. H. Chiang, D. J. Vimont, Analogous Pacific and Atlantic Meridional Modes of Tropical Atmosphere-Ocean Variability. J. Clim. 17, 4143-4158 (2004).

39. H. Zhang, A. Clement, P. Di Nezio, The south pacific meridional mode: A mechanism for ENSO-like variability. J. Clim. 27, 769-783 (2014).

40. E. Di Lorenzo, G. Liguori, N. Schneider, J. C. Furtado, B. T. Anderson, M. A. Alexander, ENSO and meridional modes: A null hypothesis for Pacific climate variability. Geophys. Res. Lett. 42, 9440-9448 (2015).

41. Y. Zhao, E. Di Lorenzo, The impacts of Extra-tropical ENSO Precursors on Tropical Pacific Decadal-scale Variability. Sci. Rep. 10, 1-12 (2020).

42. G. Liguori, E. Di Lorenzo, Separating the North and South Pacific Meridional Modes Contributions to ENSO and Tropical Decadal Variability. Geophys. Res. Lett. (2019), doi:10.1029/2018GL080320.

43. Y. M. Okumura, Origins of tropical pacific decadal variability: Role of stochastic atmospheric forcing from the South Pacific. J. Clim. 26, 9791-9796 (2013).

44. C. T. Y. Chung, S. B. Power, A. Sullivan, F. Delage, Sci. Rep., in press, doi:10.1038/s41598-019-52805-2.

45. S. McGregor, M. F. Stuecker, J. B. Kajtar, M. H. England, M. Collins, Model tropical Atlantic biases underpin diminished Pacific decadal variability. Nat. Clim. Chang. 8, 493498 (2018).

46. W. Cai, L. Wu, M. Lengaigne, T. Li, S. McGregor, J.-S. Kug, J.-Y. Yu, M. F. Stuecker, A. Santoso, X. Li, Y.-G. Ham, Y. Chikamoto, B. Ng, M. J. McPhaden, Y. Du, D.

Dommenget, F. Jia, J. B. Kajtar, N. Keenlyside, X. Lin, J.-J. Luo, M. Martín-Rey, Y. Ruprich-Robert, G. Wang, S.-P. Xie, Y. Yang, S. M. Kang, J.-Y. Choi, B. Gan, G.-I. Kim, C.-E. Kim, S. Kim, J.-H. Kim, P. Chang, Pantropical climate interactions. Science (80-. ). 363, eaav4236 (2019).

47. R. Farneti, F. Molteni, F. Kucharski, Pacific interdecadal variability driven by tropicalextratropical interactions. Clim. Dyn. 42, 3337-3355 (2014).

48. Y. Peng, C. Shen, H. Cheng, Y. Xu, Simulation of the Interdecadal Pacific Oscillation and its impacts on the climate over eastern China during the last millennium. J. Geophys. Res. Atmos. 120, 7573-7585 (2015). 
49. K. Lyu, X. Zhang, J. A. Church, J. Hu, Evaluation of the interdecadal variability of sea surface temperature and sea level in the Pacific in CMIP3 and CMIP5 models. Int. J. Climatol. 36, 3723-3740 (2016).

50. B. J. Henley, G. Meehl, S. B. Power, C. K. Folland, A. D. King, J. N. Brown, D. J. Karoly, F. Delage, A. J. E. Gallant, M. Freund, R. Neukom, Spatial and temporal agreement in climate model simulations of the Interdecadal Pacific Oscillation. Environ. Res. Lett. 12, 44011 (2017).

51. S. Power, F. Delage, C. Chung, G. Kociuba, K. Keay, Robust twenty-first-century projections of El Niño and related precipitation variability. Nature. 502, 541-5 (2013).

52. G. Kociuba, S. B. Power, Inability of CMIP5 models to simulate recent strengthening of the walker circulation: Implications for projections. J. Clim. 28, 20-35 (2015).

53. H. Bellenger, E. Guilyardi, J. Leloup, M. Lengaigne, J. Vialard, ENSO representation in climate models : from CMIP3 to CMIP5. Clim. Dyn. 42, 1999-2018 (2014).

54. S.-P. Xie, C. Deser, G. A. Vecchi, J. Ma, H. Teng, A. T. Wittenberg, Global Warming Pattern Formation: Sea Surface Temperature and Rainfall. J. Clim. 23, 966-986 (2010).

55. W. Cai, A. Santoso, G. Wang, L. Wu, M. Collins, M. Lengaigne, S. Power, A. Timmermann, in El Niño Southern Oscillation in a Changing Climate, M. J. McPhaden, A. Santoso, W. Cai, Eds. (John Wiley \& Sons, Inc., First Edit., 2021; https://doi.org/10.1002/9781119548164.ch13), pp. 289-307.

56. T. Andrews, J. M. Gregory, M. J. Webb, The dependence of radiative forcing and feedback on evolving patterns of surface temperature change in climate models. J. Clim. 28, 1630-1648 (2015).

57. G. Liguori, E. Di Lorenzo, Meridional Modes and Increasing Pacific Decadal Variability Under Anthropogenic Forcing. Geophys. Res. Lett. 45, 983-991 (2018).

58. S. Li, L. Wu, Y. Yang, T. Geng, W. Cai, B. Gan, Z. Chen, Z. Jing, G. Wang, X. Ma, The Pacific Decadal Oscillation less predictable under greenhouse warming. Nat. Clim. Chang. 10, 30-34 (2020).

59. S.-P. Xie, B. Lu, B. Xiang, Similar spatial patterns of climate responses to aerosol and greenhouse gas changes. Nat. Geosci. 6, 828 (2013).

60. M. A. Balmaseda, K. E. Trenberth, E. Källén, Distinctive climate signals in reanalysis of global ocean heat content. Geophys. Res. Lett. 40, 1754-1759 (2013).

61. D. M. Smith, B. B. B. Booth, N. J. Dunstone, R. Eade, L. Hermanson, G. S. Jones, A. A. Scaife, K. L. Sheen, V. Thompson, Role of volcanic and anthropogenic aerosols in the recent global surface warming slowdown. Nat. Clim. Chang. 6, 936 (2016).

62. W. Hua, A. Dai, M. Qin, Contributions of Internal Variability and External Forcing to the Recent Pacific Decadal Variations. Geophys. Res. Lett. 45, 7084-7092 (2018).

63. S. McGregor, M. Khodri, N. Maher, M. Ohba, F. S. R. Pausata, S. Stevenson, in El Nino Southern Oscillation in a changing climate, M. McPhaden, A. Santoso, W. Cai, Eds. (John Wile \& Sons, Inc., First Edit., 2021), vol. 253, pp. 267-287.

64. V. M. Mehta, H. Wang, K. Mendoza, Simulations of three natural decadal climate variability phenomena in CMIP5 experiments with the UKMO HadCM3, GFDL-CM2.1, NCAR-CCSM4, and MIROC5 global earth system models. Clim. Dyn. 51, 1559-1584 (2018).

65. N. Maher, A. Sen Gupta, M. H. England, Drivers of decadal hiatus periods in the 20th and 21st centuries. Geophys. Res. Lett. 41, 5978-5986 (2014).

66. G. A. Meehl, J. M. Arblaster, K. Matthes, F. Sassi, H. van Loon, Amplifying the Pacific 
Climate System Response to a Small 11-Year Solar Cycle Forcing. Science (80-. ). 325 (2009), doi:10.1126/science.1172872.

67. T. Chen, K. M. Cobb, G. Roff, J. Zhao, H. Yang, M. Hu, K. Zhao, Coral-Derived Western Pacific Tropical Sea Surface Temperatures During the Last Millennium. Geophys. Res. Lett. 45, 3542-3549 (2018).

68. G. Wang, S. B. Power, S. Mcgree, Unambiguous warming in the western tropical Pacific primarily caused by anthropogenic forcing. Int. J. Climatol. 36, 933-944 (2016).

69. E. Weller, S. K. Min, W. Cai, F. W. Zwiers, Y. H. Kim, D. Lee, Human-caused IndoPacific warm pool expansion. Sci. Adv. 2, 1-8 (2016).

70. C. Sun, F. Kucharski, J. Li, F. F. Jin, I. S. Kang, R. Ding, Western tropical Pacific multidecadal variability forced by the Atlantic multidecadal oscillation. Nat. Commun. 8 , 1-10 (2017).

71. K. M. Grise, S. M. Davis, I. R. Simpson, D. W. Waugh, Q. Fu, R. J. Allen, K. H. Rosenlof, C. C. Ummenhofer, K. B. Karnauskas, A. C. Maycock, X. W. Quan, T. Birner, P. W. Staten, Recent tropical expansion: Natural variability or forced response? J. Clim. 32, 1551-1571 (2019).

72. G. Beaugrand, A. Conversi, A. Atkinson, J. Cloern, S. Chiba, S. Fonda-Umani, R. R. Kirby, C. H. Greene, E. Goberville, S. A. Otto, P. C. Reid, L. Stemmann, M. Edwards, Prediction of unprecedented biological shifts in the global ocean. Nat. Clim. Chang. 9, 237-243 (2019).

73. B. Jebri, M. Khodri, V. Echevin, G. Gastineau, S. Thiria, J. Vialard, N. Lebas, Contributions of internal variability and external forcing to the recent trends in the southeastern pacific and peru-chile upwelling system. J. Clim. 33, 10555-10578 (2020).

74. A. G. Pendergrass, R. Knutti, F. Lehner, C. Deser, B. M. Sanderson, Precipitation variability increases in a warmer climate. Sci. Rep. 7, 1-9 (2017).

75. G. A. Vecchi, B. J. Soden, A. T. Wittenberg, I. M. Held, A. Leetmaa, M. J. Harrison, Weakening of tropical Pacific atmospheric circulation due to anthropogenic forcing. 441 (2006), doi:10.1038/nature04744.

76. U. K. Heede, A. V. Fedorov, N. J. Burls, Time Scales and Mechanisms for the Tropical Pacific Response to Global Warming: A Tug of War between the Ocean Thermostat and Weaker Walker. J. Clim. 33, 6101-6118 (2020).

77. M. F. Stuecker, A. Timmermann, F. F. Jin, C. Proistosescu, S. M. Kang, D. Kim, K. S. Yun, E. S. Chung, J. E. Chu, C. M. Bitz, K. C. Armour, M. Hayashi, Strong remote control of future equatorial warming by off-equatorial forcing. Nat. Clim. Chang. 10, 124129 (2020).

78. E. S. Chung, A. Timmermann, B. J. Soden, K. J. Ha, L. Shi, V. O. John, Reconciling opposing Walker circulation trends in observations and model projections. Nat. Clim. Chang. 9, 405-412 (2019).

79. C. Takahashi, M. Watanabe, Pacific trade winds accelerated by aerosol forcing over the past two decades. Nat. Clim. Chang. 6, 768-772 (2016).

80. L. Dong, M. J. McPhaden, Why has the relationship between Indian and Pacific Ocean decadal variability changed in recent decades? J. Clim. 30, 1971-1983 (2017).

81. T. Kohyama, D. L. Hartmann, D. S. Battisti, La Niña-like mean-state response to global warming and potential oceanic roles. J. Clim. 30, 4207-4225 (2017).

82. A. C. Clement, R. Seager, M. A. Cane, S. E. Zebiak, An ocean dynamical thermostat. J. Clim. 9, 2190-2196 (1996). 
83. R. Seager, M. Cane, N. Henderson, D. E. Lee, R. Abernathey, H. Zhang, Strengthening tropical Pacific zonal sea surface temperature gradient consistent with rising greenhouse gases. Nat. Clim. Chang. 9, 517-522 (2019).

84. J. J. Luo, G. Wang, D. Dommenget, May common model biases reduce CMIP5's ability to simulate the recent Pacific La Niña-like cooling? Clim. Dyn. 50, 1335-1351 (2018).

85. N. Bellouin, J. Quaas, E. Gryspeerdt, S. Kinne, P. Stier, D. Watson-Parris, O. Boucher, K. S. Carslaw, M. Christensen, A. L. Daniau, J. L. Dufresne, G. Feingold, S. Fiedler, P. Forster, A. Gettelman, J. M. Haywood, U. Lohmann, F. Malavelle, T. Mauritsen, D. T. McCoy, G. Myhre, J. Mülmenstädt, D. Neubauer, A. Possner, M. Rugenstein, Y. Sato, M. Schulz, S. E. Schwartz, O. Sourdeval, T. Storelvmo, V. Toll, D. Winker, B. Stevens, Bounding Global Aerosol Radiative Forcing of Climate Change. Rev. Geophys. 58, 1-45 (2020).

86. J. Emile-Geay, K. M. Cobb, J. E. Cole, M. Elliot, F. Zhu, in El Niño Southern Oscillation in a Changing Climate, M. J. McPhaden, A. Santoso, W. Cai, Eds. (John Wiley and Sons, Inc., First., 2021), vol. 253, pp. 87-118.

87. P. N. DiNezio, C. Deser, A. Karspeck, S. Yeager, Y. Okumura, G. Danabasoglu, N. Rosenbloom, J. Caron, G. A. Meehl, P. N. Di Nezio, C. Deser, A. Karspeck, S. Yeager, Y. Okumura, G. Danabasoglu, N. Rosenbloom, J. Caron, G. A. Meehl, Geophys. Res. Lett., in press, doi:10.1002/2017GL074904.

88. A. A. Scaife, D. Smith, A signal-to-noise paradox in climate science. npj Clim. Atmos. Sci. 1 (2018), doi:10.1038/s41612-018-0038-4.

89. D. M. Smith, R. Eade, A. A. Scaife, L.-P. Caron, G. Danabasoglu, T. M. DelSole, T. Delworth, F. J. Doblas-Reyes, N. J. Dunstone, L. Hermanson, V. Kharin, M. Kimoto, W. J. Merryfield, T. Mochizuki, W. A. Müller, H. Pohlmann, S. Yeager, X. Yang, Robust skill of decadal climate predictions. npj Clim. Atmos. Sci. 2, 1-10 (2019).

90. R. Séférian, L. Bopp, M. Gehlen, D. Swingedouw, J. Mignot, E. Guilyardi, J. Servonnat, Proc. Natl. Acad. Sci., in press, doi:10.1073/pnas.1315855111.

91. N. S. Lovenduski, S. G. Yeager, K. Lindsay, M. C. Long, Predicting near-term variability in ocean carbon uptake. Earth Syst. Dynam. 10, 45-57 (2019).

92. Y. Chikamoto, T. Mochizuki, A. Timmermann, M. Kimoto, M. Watanabe, Potential tropical Atlantic impacts on Pacific decadal climate trends. Geophys. Res. Lett. 43, 71437151 (2016).

93. G. A. Meehl, H. Teng, CMIP5 multi-model hindcasts for the mid-1970s shift and early 2000s hiatus and predictions for 2016-2035. Geophys. Res. Lett. 41, 1711-1716 (2014).

94. M. Thoma, R. J. Greatbatch, C. Kadow, R. Gerdes, Decadal hindcasts initialized using observed surface wind stress: Evaluation and prediction out to 2024. Geophys. Res. Lett. 42, 6454-6461 (2015).

95. G. A. Meehl, A. Hu, H. Teng, Initialized decadal prediction for transition to positive phase of the Interdecadal Pacific Oscillation. Nat. Commun. 7, 1-7 (2016).

96. N. A. Rayner, D. E. Parker, E. B. Horton, C. K. Fooland, L. V. Alexander, D. P. Rowell, E. C. Kent, A. Kaplan, Global analyses of SST, sea ice, and night marine air temperature since the late nineteenth century. J. Geophys. Res. 108, 4407 (2003).

97. M. A. Balmaseda, K. Mogensen, A. T. Weaver, Evaluation of the ECMWF ocean reanalysis system ORAS4. Q. J. R. Meteorol. Soc. 139, 1132-1161 (2013).

98. E. de Boisséson, M. A. Balmaseda, M. Mayer, Ocean heat content variability in an ensemble of twentieth century ocean reanalyses. Clim. Dyn. 50, 3783-3798 (2018). 
99. G. P. Compo, J. S. Whitaker, P. D. Sardeshmukh, N. Matsui, R. J. Allan, X. Yin, B. E. Gleason, R. S. Vose, G. Rutledge, P. Bessemoulin, S. Brönnimann, M. Brunet, R. I. Crouthamel, A. N. Grant, P. Y. Groisman, P. D. Jones, M. C. Kruk, A. C. Kruger, G. J. Marshall, M. Maugeri, H. Y. Mok, Ø. Nordli, T. F. Ross, R. M. Trigo, X. L. Wang, S. D. Woodruff, S. J. Worley, The Twentieth Century Reanalysis Project. Q. J. R. Meteorol. Soc. 137, 1-28 (2011).

100. P. Poli, H. Hersbach, D. P. Dee, P. Berrisford, A. J. Simmons, F. Vitart, P. Laloyaux, D. G. H. Tan, C. Peubey, J.-N. Thépaut, Y. Trémolet, E. V Hólm, M. Bonavita, L. Isaksen, M. Fisher, ERA-20C: An Atmospheric Reanalysis of the Twentieth Century. J. Clim. 29, 4083-4097 (2016).

\section{ACKNOWLEDGEMENTS}

We wish to thank Jing Li at WCRP for helping to organise workshops to help advance this review, the first at Centro Nacional de Acuiccultura e Investigaciones Marinas (CENAIM) and Escuela Superior Politecnica del Litoral (ESPOL) in Ecuador, the second at LOCEAN-IPSL,

Sorbonne University in Paris, both Viatcheslav Kharin and George Boer for providing the data used in Fig. 5A, Giovanni Liguoro and Julien Cretat, for reviewing earlier drafts, Pascale Bracannot for discussions regarding paleoclimate, Roland Séférian for discussions regarding biogeochemistry, and Lea Crosswell for finalizing the Summary figure. Thanks also to reviewers for their very helpful and constructive comments. Funding: S.P., W.C., F.D., and C.C. were partially supported by the Earth System and Climate Change Hub of the Australian National Environmental Science Programme. W.C., W.G. and X.Z. were supported by CSHOR, a joint research Centre for Southern Hemisphere Oceans Research between QNLM and CSIRO. M.L., J.V. and E.G. were supported by the Agence Nationale de la Recherche ARISE project, under grant ANR-18-CE01-0012, and the Belmont project GOTHAM, under grant ANR-15-JCLI0004-01. A.C. was supported by the NOAA Climate Program Office's Climate Variability and Predictability (CVP) and Modeling, Analysis, Predictions and Projections (MAPP) Programs. M.C. was supported by NE/N018486/1 and NE/N005783/1. This is PMEL contribution no. 5031. G.M. was partially supported by the Regional and Global Model Analysis (RGMA) component 
828 of the Earth and Environmental System Modeling Program of the U.S. Department of Energy's

829 Office of Biological \& Environmental Research via National Science Foundation IA 1844590, 830 and by NCAR, which is a major facility sponsored by the National Science Foundation under 831 Cooperative Agreement No. 1852977. S.McG. was supported by the Australian Research 832 Council through grant FT160100162 and DP20. Y.O. was supported by the NOAA Climate 833 Program Office's Modeling, Analysis, Predictions, and Projections Program 834 (NA17OAR4310149) and the NSF Physical Oceanography Program (OCE-1756883). B.H. was 835 supported by an Australian Research Council Linkage Project (LP150100062). M.N. was 836 partially supported by US Department of Energy Grant \#0000238382. J.J.Ll was supported by 837 National Natural Science Foundation of China (Grants 42088101 and 42030605). D.S. was 838 supported by the Met Office Hadley Centre Climate Programme funded by BEIS and DEFRA. 


\section{Figure captions}

852

853

Fig. 1. Observed decadal variability in the tropical Pacific. (A) 1992-2009 linear trend of

854

855

856

857

858

859

860

861

862

863

864

865

866

867

868

869

870

871 annual SST (shading, $0.1^{\circ} \mathrm{C}$ decade $^{-1}$ ) and sea surface height (black contours, $2 \mathrm{~cm} \mathrm{decade}$, $^{-1}$ dashed contours indicate negative trends, solid contours denote positive trends, and the zero contour is omitted). (B) 8 yr lowpass and (C) 8-40 yr bandpass filtered SST variance (black contours, in $10^{2}$ ${ }^{\circ} \mathrm{C}^{2}$ ) and ratio of the filtered SST variance to total SST variance (shading). (D) 8 yr lowpass filtered timeseries of SST averaged over the Niño34 region $\left(5^{\circ} \mathrm{N}-5^{\circ} \mathrm{S} ; 170^{\circ} \mathrm{W}-120^{\circ} \mathrm{W}\right)$, the western tropical Pacific $\left(10^{\circ} \mathrm{N}-10^{\circ} \mathrm{S} ; 120^{\circ} \mathrm{E}-150^{\circ} \mathrm{E}\right)$ and over the globe from instrumental observations (black lines) and Last Millennium Reconstruction ((19); mean: grey line; interquartile range: light grey shading) and of $\delta^{18} \mathrm{O}$ at Palmyra and Fiji islands (plain and dashed blue lines; positions indicated in (A); $(17,18))$. Vertical red and blue bands indicate positive and negative phases of the Interdecadal Pacific Oscillation. SST data: HadISST (96). SSH data: ORAS4 dataset (97).

Fig. 2. Internal TPDV - the null hypothesis. (A) Pacific SST pattern associated with internal TPDV, obtained by regressing the 8-40 year band-pass filtered SST anomalies onto the internal TPDV index. The latter is obtained as the time series (or Principal Component) of the leading EOF of SST anomalies in the $8-40$ year band, over the tropical Pacific $\left(24^{\circ} \mathrm{S}-24^{\circ} \mathrm{N} ; 120^{\circ} \mathrm{E}-80^{\circ} \mathrm{W}\right)$. (B) Timeseries of SST anomalies averaged in the Niño34 region $\left(5^{\circ} \mathrm{S}-5^{\circ} \mathrm{N}, 170^{\circ} \mathrm{W}-120^{\circ} \mathrm{W} ; \mathrm{N} 3.4\right)$, a commonly used SST ENSO index; the Southern Oscillation Index (SOI; (18)), a measure of the Walker Circulation strength; the internal TPDV index, and the E-L index, defined as the number 
872 of El Niño years minus the number of La Niña years over 8-year running periods. ENSO events 873 are identified using the December Niño3.4 index and an amplitude threshold of 1 standard 874 deviation. Thick black lines in (B) indicate the 8-40year band-pass filtered time series. (C) Average 875 of ENSO-related SST anomalies over the year preceding the peak of an El Niño event (year 0) and

876 the year following the El Niño event (year 1), defined by computing lagged regressions of SST 877 onto the November-December-January averaged N3.4 index from lags of $-11 \mathrm{mo}$ to $+12 \mathrm{mo}$, and 878 averaging over all 24 resulting maps. (D), (E), and (F) show individual SST maps from these 879 monthly regressions, illustrating precursor anomalies during the February-March-April (FMA, D) 880 prior to the peak of an event, peak anomalies during October-November-December (OND, E) of 881 the ENSO event, and anomalies during the decay phase in June-July-August (JJA, F) of the years 882 following the peak of an ENSO event. The SST data are from HadISST (96) over the period 1900883 2020. Filtering was performed using 5 and 53 point Hanning filter weights.

Fig. 3. Mechanisms of internal and external TPDV. (A) Schematic representation of the ocean processes associated with internal TPDV. The climatological upper ocean overturning circulation 887 (the Subtropical-Tropical Cells, transparent blue arrows) consists of a subtropical subduction 888 component, equatorward subsurface transport, equatorial upwelling, and a poleward surface return flow driven by the equatorial easterly trade winds (large blue arrow), which are the surface 890 component of the Walker Circulation. A positive phase of internal TPDV with warm SST in the 891 tropical Pacific (shading) is associated with a weaker Walker Circulation, reduced equatorial 892 winds, and weaker oceanic overturning circulation. Extra-equatorial wind anomalies may play an 893 important role in driving the changes in the Subtropical-Tropical Cells, whose adjustment is 
accomplished through the westward propagation of oceanic Rossby waves. After reaching the western boundary, Rossby waves can continue along the boundary to the equator as coastal Kelvin waves and along the equator as equatorial Kelvin waves. The extra-equatorial wind anomalies may be purely stochastic, arise from extra-tropical influences, or as a response to equatorial SST anomalies (see text for details). (B) Schematic representation of projected changes associated with external TPDV. The map shows the late $21^{\text {st }}$ century multi-model-mean change in CMIP6 SST, which is dominated by increases in greenhouse gases. High (low) confidence in these projected changes is indicated by solid (dashed) lines. Icons indicate the major external forcings involved in these changes. Greenhouse gas increases and ozone changes induce a robust southward expansion of the Hadley Cell in the southern hemisphere and reduced southern subtropical Pacific warming, in both model projections and observations. The prominent western Pacific warming and the central Pacific rainfall increase detected in models and observations can confidently be attributed greenhouse gas increases. While the projected weakening and enhanced tropical warming is evident in most CMIP6 models, confidence in these projections is low because of inconsistent signals in observations, model biases and the complexity of the mechanisms involved. Volcanic eruptions and changes in solar insolation may also cause decadal variations in the tropical Pacific, though their amplitude is likely small.

Fig. 4. Evaluation of internal TPDV in CMIP models. Maps of the $1^{\text {st }}$ EOF of 8-40yrs bandpass filtered SST over the tropical Pacific (shading), and associated sea-level (contours) and 2m wind (vectors) variability for (A) observations $(96,98,99)$ and (B) a multi-model mean of (10). Box plot showing median, interquartile range, maximum and minimum of CMIP6 historical simulations for $(\mathbf{C})$ the standard deviation of the TPDV index, and (D) the correlation coefficients 
917 between E-L and the internal TPDV index. E-L is a measure of the extent to which El Niño 918 dominates each 8-yr period and is defined as $n(E N)-n(L N)$, where $n(E N)=$ the number of El Niño 919 years and $\mathrm{n}(\mathrm{LN})=$ the number of La Niña years in eight-year blocks. ENSO events are defined using 920 a threshold of 1 STD of Nino3.4 SST. The TPDV index is defined here as the first principal 921 component of the 8-40yrs bandpass filtered SST EOF analysis. Observations are shown as a red 922 star.

923

Fig. 5. Detection and attribution of long-term trends in the tropical Pacific. (A) Observed (96, 925 98, 99) and (B) multi-model mean (10) maps of 1900-2009 linear trends of SST (shading) and 926 surface winds (vectors) over the Tropical Pacific. Annual time series for CMIP6 historical 927 simulations (grey) and observations (colored) of the SST averaged over (C) over the Niño34 region $928\left(5^{\circ} \mathrm{N}-5^{\circ} \mathrm{S} ; 170^{\circ} \mathrm{W}-120^{\circ} \mathrm{W}\right)$ and $(\mathbf{E})$ the western tropical Pacific $\left(10^{\circ} \mathrm{N}-10^{\circ} \mathrm{S} ; 120^{\circ} \mathrm{E}-150^{\circ} \mathrm{E}\right)$, the 929 latitude of southern hemisphere Hadley Cell's poleward edge (D) and the strength of equatorial 930 zonal (east-west) winds (F). The latitude of southern hemisphere Hadley Cell's poleward edge the 931 latitudinal anomalies of the latitude where zonal mean precipitation-evaporation is zero while the 932 strength of equatorial zonal (east-west) winds is diagnosed from the $10 \mathrm{~m}$ zonal wind anomalies 933 in the Niño3.4 region (positive values indicate a weakening Walker Circulation). CMIP6 results: 934 ensemble mean (black lines); 60\% (dark blue shading) and 90\% (light blue shading) confidence 935 intervals using a t-distribution. Reanalysis: NOAA-20C (red) (99) and ERA-20C (blue) (100); red 936 lines: annual anomalies (thin lines); and 8-yr running averages (thick lines). SST data: HadISST 937 (96). Notice how the spread of model simulations is larger in the Niño3.4 region than in the western 938 Pacific. The Hadley Cell is calculated over all longitudes, not just the Pacific. 
940 Fig. 6. Predicting TPDV. (A) Actual (solid lines) and potential (dashed lines) correlation skill for 941 the surface air temperature averaged over the tropical Pacific as a function of lead time, for 942 initialized forecasts (red) and for uninitialized simulations (blue), estimated using methods 943 described previously (15). The difference between the initialized and uninitialized simulations is 944 an indication of the potential for forecast improvement (15). (B) Correlation skill score using 8945 year running mean observations of near-surface air temperature and forecast years 2-9 from 946 initialised multi-model decadal predictions. Skill is measured using the mean of 71 ensemble 947 members from seven modelling systems (89). Darker red indicates higher estimated skill. 948 Hindcasts (2) starting every year from 1960 to 2005, with observations described previously (89). 949 Stippling: outside $95 \%$ confidence interval.

950

951

952

953

954

955

956

957

958

959

960

961

962 
963

964

965 